\title{
Therapeutic Response of Triple Drug Therapy in Hepatitis C Infection
}

\author{
Shemane H Fritz ${ }^{1,2}$, Pamela H Koerner ${ }^{1 *}$, Richard T Miller ${ }^{2}$ and Zoie Craft ${ }^{2}$ \\ ${ }^{1}$ Division of Clinical, Social and Administrative Sciences, Duquesne University Mylan School of Pharmacy Bayer Learning Center, Forbes Avenue Pittsburgh, USA \\ ${ }^{2}$ Walgreens Specialty Pharmacy, Noblestown Road, Carnegie, USA
}

Received: January 04, 2014; Accepted: March 03, 2014; Published: March 12, 2014

"Corresponding author: Pamela H Koerner, Division of Clinical, Social and Administrative Sciences, Duquesne University Mylan School of Pharmacy 315 Bayer Learning Center, 600 Forbes Avenue Pittsburgh, PA 15282, USA; Tel: 412-396-6372; Fax: 412-396-5130; Email: koerner@duq.edu

\begin{abstract}
Objective: To analyze the SVR rates and medication experience in patients treated with boceprevir or telaprevir, in combination with ribavirin and peginterferon alfa for HCV infection.

Materials and methods: This study was a retrospective observational study in a United States specialty pharmacy, from July 2011 through June 2012. The primary outcome for this study was sustained virologic response (SVR) obtained through prescriber confirmation. 2,004 patients receiving treatment for hepatitis C infection that were eighteen years of age and older, with prescription claims for ribavirin, pegylated interferon and a protease inhibitor (boceprevir or telaprevir) between July 1, 2011 and June 30, 2012 were initially included in the study.

Results: SVR was achieved in $67 \%$ of patients analyzed which was significantly different from previous study rates seen in dual therapy. The most commonly reported adverse effect leading to discontinuation of therapy in the 138 patients that discontinued was hematologic adverse effects. Patients were more than $90 \%$ adherent to each medication in the regimen overall. SVR based on therapeutic regimen and medication possession ratio were also evaluated.

Conclusion: Patients on protease inhibitor-based triple therapy for the treatment of genotype 1 hepatitis C infection had significantly improved SVR rates compared to previous published dual therapy rates. These findings support the American Association for the Study of Liver Diseases (AASLD) guideline recommendation for use of protease inhibitors.
\end{abstract}

Keywords: Hepatitis C; HCV; Boceprevir; Telaprevir; SVR

\section{Introduction}

In the United States, hepatitis C (HCV) infection is the most common chronic blood borne infection and the leading cause of viral hepatitis and liver transplantation [1]. HCV is a contagious viral infection of the liver caused by the single-stranded ribonucleic acid (RNA) hepatitis $\mathrm{C}$ virus. According to the World Health Organization's estimate there are approximately 180 million people worldwide who are infected with HCV, representing $3 \%$ of the world's population [1]. With 2.7 million people chronically infected with HCV in the United States, it is four times more common than human immunodeficiency virus (HIV). There are currently six different genotypes and more than
50 different subtypes of HCV identified [2]. Genotype distribution differs worldwide, approximately $75 \%$ of the cases in the United States are genotype 1 which is historically the most difficult to treat [3].

The epidemiology of HCV infection in the United States has changed dramatically since the virus was first identified in 1989 [4]. As a blood borne pathogen, HCV is transmitted through percutaneous contact with infected blood. Prior to the development of universal precautions and screening of blood products in 1992, HCV could be transmitted to those who received blood transfusions, transplanted organs or other blood products. Today, other risk factors for HCV infection include intravenous drug use, unsterile tattoos or piercings, chronic hemodialysis, percutaneous exposure to HCV infected blood due to needle sticks in a healthcare setting and being born to an HCV infected mother [5].

In the United States, the last reported surveillance of HCV in 2010 approximated 17,000 new cases in that year alone [5]. Although the incidence of new cases of HCV infection has recently declined, increased reports of chronic infection has prompted the Centers for Disease Control and Prevention (CDC) to update the screening recommendations in August of 2012. It is now recommended that all persons born between 1945 and 1965 be screened once for HCV infection even in the absence of other risk factors [6,7]. This is because many patients chronically infected with HCV are unaware of their HCV status since they are typically asymptomatic despite the increasing damage to their liver. People born during that time frame represent $75 \%$ of the adults infected with hepatitis $\mathrm{C}$ [6]. The goal of this recommendation is to identify and treat the HCV infection before the infection leads to potentially costly and fatal complications.

The surrogate marker of sustained virologic response (SVR) defines successful treatment of the virus, or cure, 24 weeks after treatment has ended. SVR indicates that the virus has been suppressed to an undetectable level in the blood and is the most impactful indicator of future clinical outcomes. Studies have shown that maintaining SVR is associated with a decreased risk of severe complications including fibrosis of the liver, cirrhosis and hepatocellular carcinoma [8-10]. 
Prior to the 2011 approval of protease inhibitors, boceprevir (Victrelis ${ }^{\circledR}$-Merck) and telaprevir (Incivek ${ }^{\circledR}$-Vertex), for the treatment of HCV genotype 1 infection, SVR was achieved in approximately $38-45 \%$ of those treated with standard dual therapy of pegylated interferon alfa and ribavirin [10-12]. A key labeling trial for telaprevir in treatment naive patients showed an SVR rate of $75 \%$ in patients that received telaprevir combined with peginterferon alfa-2a and ribavirin for 12 weeks followed by peginterferon alfa- $2 \mathrm{a}$ and ribavirin alone for 12 weeks versus $44 \%$ in patients receiving dual therapy without a protease inhibitor [15]. Similar significant response rate differences were also reported in the labeling clinical trial information for boceprevir [16,17].

Boceprevir and telaprevir have demonstrated substantially increased rates of SVR in clinical trials when added to the standard dual therapy in HCV genotype 1 patients, however post marketing surveillance of SVR rates are only beginning to be studied [13-18]. In such patients, outside of the strict monitoring confinements of clinical trials, other factors including adherence to the complex regimen and management of adverse events may impact overall success rates. A retrospective analysis of dual therapy adherence rates and SVR showed significantly higher rates of SVR in patients that were $80 \%$ or more adherent to their pegylated interferon and ribavirin dose compared to those that were not. That analysis also found that the main reasons for not achieving adherence goals were adverse events to therapy [1921].

Although the rates of SVR have improved with the addition of protease inhibitors to dual therapy, protease inhibitors have also added to the complexity of the regimen, side effect burden and overall costs associated with HCV therapy. All of these additional issues can often cause patients to become non-adherent or even discontinue therapy [16]. In addition to the flu-like symptoms, fatigue and anemia commonly seen with dual therapy, patients on triple therapy are potentially at risk for experiencing the adverse effects of the protease inhibitors as well. One of the most common adverse effects seen with boceprevir and telaprevir is anemia (45-50\% and 36\% respectively) [21,22]. Telaprevir patients have also reported skin disorders including rash (56\%), pruritus (47\%) and anal pruritus (6\%) [21,22]. Recent reports of severe rash associated with telaprevir use prompted a labeling change to include a black box warning to discontinue therapy in patients who develop a rash with systemic symptoms or a progressive severe rash.

Based on newly available clinical data with the protease inhibitors, an update to the guidelines by the American Association for the Study of Liver Disorders was published in 2011 for genotype $1 \mathrm{HCV}$ patients [23]. The recommendation states that treatment-naïve patients should receive boceprevir or teleprevir in combination with peginterferon alfa and ribavirin [23]. The guidelines also provide guidance for the use of the protease inhibitors in treatment-experienced patients.

\section{Objective}

The objective of this study was to analyze the SVR rates and medication experience in patients treated with boceprevir or telaprevir, in combination with ribavirin and peginterferon alfa for HCV infection.

\section{Methods}

This retrospective observational study was conducted utilizing the claims data of a national specialty pharmacy. Participants included patients from throughout the continental United States. All subjects included in the study received a Notice of Privacy Practice and signed HIPAA authorization allowing the use of their de-identified data for study purposes. The study was evaluated and approved by an Institutional Review Board prior to study initiation. Prior to statistical analysis all data collected was de-identified to protect subject identity. Funding was not provided for this study from any secondary source.

Patients who were 18 years of age and older, with prescription claims for ribavirin, pegylated interferon and a protease inhibitor (boceprevir or telaprevir) between July 1, 2011 and June 30, 2012, were initially identified for inclusion in the study. Data was extracted utilizing a claims processing system, clinical assessment management system and via fax-based outreach to prescribers. Demographic information, adverse events and laboratory data were obtained through clinical pharmacy records. As standard of care for the management of HCV patients at this specialty pharmacy, patients are enrolled in a clinical management program that tracks their viral loads (at therapy initiation and weeks $4,8,12,24$, and 48), adherence to therapy and adverse events via telephonic-based clinical assessments and fax outreach to the prescriber. Patients may opt out of this service at any point. Patients whom opted out of the clinical management program were not included in this study. For the purpose of this study, additional outreach to the prescriber via fax was conducted to obtain genotype, viral loads, and reasons for therapy discontinuation when not documented in the pharmacy's clinical system. Patients with final fill dates at least 6 months prior to the date of data collection were considered eligible for SVR, 24 weeks after completing therapy, and outreach to the prescriber was conducted to determine if SVR was achieved. For those patients, prescribers were asked to indicate on the fax response if the patient had achieved SVR, did not achieve SVR or were ineligible due to discontinuing therapy.

As a result of the need for strict adherence with triple therapy, the medication possession ratio (MPR), a surrogate marker for adherence, was calculated for each medication in the patient's regimen if they were eligible for SVR analysis. Medication possession ratio is a ratio of the day's supply on hand over a given time period. Medication possession ratios greater than $80 \%$ were considered adherent.

The primary outcome for this study was sustained virologic response (SVR) obtained through prescriber confirmation. Secondary measures included initial viral loads, genotype, treatment adherence, reasons for therapy discontinuation and adverse events experienced in patients that discontinued therapy due to adverse reactions. Adverse events were grouped into the following six categories commonly experienced with hepatitis 
therapies: hematologic, rash, mental health, gastrointestinal symptoms, allergic reactions and flu-like symptoms. Hematologic adverse effects included anemia, neutropenia and other blood dyscrasias. Rash included any dermatologic event regardless of severity. Mental health category included depression and psychiatric conditions. Gastrointestinal symptoms included diarrhea, nausea, and any other adverse event related to the gastrointestinal system. Finally, flu-like symptoms included fatigue, weakness, chills, malaise, and loss of appetite.

\section{Statistical analysis}

Descriptive statistics were used to analyze the patient demographic data including gender, age, genotype, initial viral load, and therapy choice (ribavirin, pegylated interferon products and protease inhibitor). IBM ${ }^{\circledR}$ SPSS $^{\circledR}$ Statistics version 21.0 was used for all data analysis. A one-tailed $\mathrm{z}$ approximation test was conducted to compare proportion of study population that achieved SVR to standard probability as well as historic SVR rates (38-45\%) achieved with dual therapy in previous trials [12].

\section{Results}

A total of 2,004 patients were initially identified as having at least one claim for ribavirin, pegylated interferon and either boceprevir or telaprevir dispensed from the pharmacy during the study period (Figure 1). Patients who did not complete their treatment program or whose prescriber provided insufficient information were ineligible for participation in the study. A total of $1,598(80 \%)$ patients were excluded from the study. Analysis showed that 1,239 (77\%) patients were identified as not having completed therapy and 359 (23\%) patients had no response received back from their prescriber after multiple attempts to contact. Of those 1,239 patients that did not complete therapy; 464 (37\%) had exclusions unrelated to therapy, 366 (30\%) discontinued therapy and 409 (33\%) were still on therapy however were not 6 months post therapy at the time of data collection and SVR could not yet be determined. Exclusions unrelated to therapy included 336 patients that transferred pharmacies, 57 whom opted out of clinical management, 11 were deceased, 14 never started therapy and 46 were only receiving their protease inhibitor from the specialty pharmacy.

The remaining 406 total patients were determined to be eligible for SVR analysis. Of those patients $60.3 \%$ were male, $39.7 \%$ female, and $92.6 \%$ were classified as genotype 1 . When evaluating viral load at start of therapy, $45.6 \%$ were identified as having a high initial viral load (defined as a viral load greater than $800,000 \mathrm{IU} / \mathrm{mL}$ ) and $20.7 \%$ were classified as low (defined as a viral load less than $800,000 \mathrm{IU} / \mathrm{mL}$ ) with the remaining $33.7 \%$ unreported (Table 1). Patients were categorized as unreported if viral load could not be located in the pharmacy system or not provided by the physician upon contacting them. More than three times as many patients $(316 ; 77.8 \%)$ were on the telaprevirbased regimen therapy than were on the boceprevir-based regimen $(90 ; 22.2 \%)$.

The overall SVR rate in this study was $67 \%$ for triple therapy including either boceprevir or telaprevir (Table 2). Of the total 134 patients who did not achieve SVR, $44.8 \%$ of patients discontinued therapy due to inadequate viral response, $37.3 \%$ had a detectable viral load after completing therapy and $17.9 \%$ were reported as failing treatment without documented reason (Figure 1). Additional analyses were conducted to determine SVR rates for specific therapy choices summarized in table 3 . The observed SVR rates for telaprevir and boceprevir based therapy were $69.3 \%$ and $58.9 \%$ respectively. Of the total 406 patients analyzed for SVR results, $79.6 \%$ were on peginterferon alfa-2a as their interferon product, of which $68.4 \%$ achieved SVR. Eightythree patients were on peginterferon alfa- $2 \mathrm{~b}$ of which $61.4 \%$ achieved SVR (Table 4). However, it is important to note, that the study was not designed to look at individual drug therapy response.

Analysis was conducted to determine if the observed proportion of patients that achieved SVR was different from the $38-45 \%$ that achieved SVR in previous research of dual therapy [5-7]. The observed proportion of patients that achieved SVR, $67 \%$ differed significantly from $38 \%$ and $45 \%$, with a one-tailed $\mathrm{p}=0.021$ and 0.0001 respectively (Table 5).

The most prevalent reported reason for therapy discontinuation was adverse events. The 138 patients that discontinued treatment due to side effects were analyzed

\begin{tabular}{|c|c|}
\hline \multicolumn{2}{|c|}{ Table 1: Population Demographics. } \\
\hline Age (years) & \\
\hline Average & 53 \\
\hline Range & $21-70$ \\
\hline Gender & $n(\%)$ \\
\hline Male & $245(60.3)$ \\
\hline Female & $161(39.7)$ \\
\hline Genotype & $n(\%)$ \\
\hline 1 & $376(92.6)$ \\
\hline Other & $3(0.7)$ \\
\hline Unreported & $27(6.7)$ \\
\hline Initial Viral Load (IU/mL) & $n(\%)$ \\
\hline High $(>800,000)$ : & $185(45.6)$ \\
\hline Low $(<800,000)$ : & $84(20.7)$ \\
\hline Unreported: & $137(33.7)$ \\
\hline Protease Inhibitor & $n(\%)$ \\
\hline Boceprevir & $90(22.2)$ \\
\hline Telaprevir & $316(77.8)$ \\
\hline
\end{tabular}

Table 2: Crosstab Treatment result vs. Protease inhibitor.

\begin{tabular}{|c|c|c|c|c|c|}
\hline & & & \multicolumn{2}{|c|}{ Protease Inhibitor } & \multirow{2}{*}{\begin{tabular}{|c|} 
Total \\
$\mathbf{N}=406$
\end{tabular}} \\
\hline & & & telaprevir & boceprevir & \\
\hline \multirow{4}{*}{$\begin{array}{c}\text { Treatment } \\
\text { Success vs. Fail }\end{array}$} & \multirow{2}{*}{$\begin{array}{c}\text { SVR } \\
\text { Achieved }\end{array}$} & Count & 219 & 53 & 272 \\
\hline & & & $69.3 \%$ & $58.9 \%$ & $67.0 \%$ \\
\hline & \multirow{2}{*}{$\begin{array}{l}\text { Failed } \\
\text { Therapy }\end{array}$} & Count & 97 & 37 & 134 \\
\hline & & & $30.7 \%$ & $41.1 \%$ & $33.0 \%$ \\
\hline Total & & Count & 316 & 90 & 406 \\
\hline
\end{tabular}




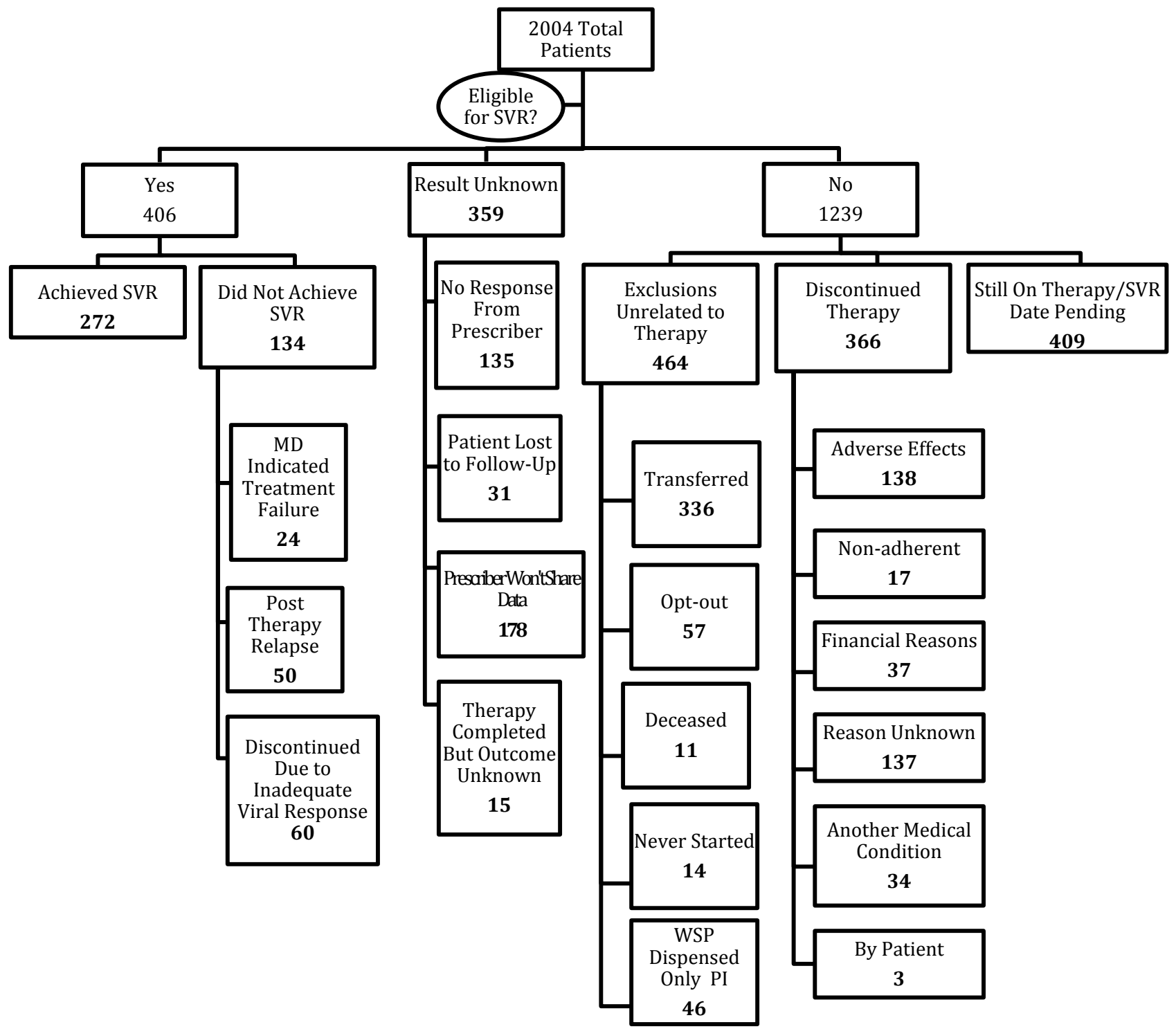

Figure 1: Total Study Population.

Table 3: SVR results for each therapy.

\begin{tabular}{|l|l|c|c|c|c|}
\hline \multirow{2}{*}{ Protease Inhibitor } & Interferon Therapy & Ribavirin Therapy & N & $\begin{array}{c}\text { SVR Achieved } \\
(\%)\end{array}$ & $\begin{array}{c}\text { SVR Not Achieved } \\
\text { (\%) }\end{array}$ \\
\hline \multirow{5}{*}{ Boceprevir } & Peginterferon alfa 2a & Ribavirin tablets & 31 & $(54.8 \%)$ & $(45.2 \%)$ \\
\cline { 2 - 6 } & Peginterferon alfa 2a & Ribavirin capsules & 21 & $(61.9 \%)$ & $(38.1 \%)$ \\
\cline { 2 - 6 } & Peginterferon alfa 2b & Ribavirin tablets & 27 & $(59.3 \%)$ & $(40.7 \%)$ \\
\cline { 2 - 6 } & Peginterferon alfa 2b & Ribavirin capsules & 10 & $(60.0 \%)$ & $(40.0 \%)$ \\
\hline \multirow{5}{*}{ Telaprevir } & Peginterferon alfa 2a & Ribavirin tablets & 175 & $(69.7 \%)$ & $(30.3 \%)$ \\
\cline { 2 - 6 } & Peginterferon alfa 2a & Ribavirin capsules & 94 & $(71.3 \%)$ & $(28.7 \%)$ \\
\cline { 2 - 6 } & Peginterferon alfa 2b & Ribavirin tablets & 27 & $(55.6 \%)$ & $(44.4 \%)$ \\
\cline { 2 - 6 } & Peginterferon alfa 2b & Ribavirin capsules & 18 & $(72.2 \%)$ & $(27.8 \%)$ \\
\hline
\end{tabular}


separately from the SVR eligible analysis. Hematologic adverse effects were the most highly reported adverse effects associated with the discontinuation of telaprevir and boceprevir based therapies with 32 and 10 patients discontinuing respectively (Table 6). Twenty-three telaprevir patients discontinued therapy due to the development of a rash. Flu-like symptoms were the least frequently reported reasons for discontinuation for both telaprevir and boceprevir with five and three patients discontinuing respectively.

Analysis of MPR indicated average MPR was greater than $90 \%$ overall for each medication (Table 7). MPR was calculated based on dispensing data in the pharmacy claims system.

\section{Discussion}

The observed results of this study were similar to triple therapy clinical trial results and provide evidence of higher efficacy

Table 4: Crosstab Treatment result vs. Interferon product.

\begin{tabular}{|c|c|c|c|c|}
\hline & & & \multicolumn{2}{|c|}{ Interferon Product } \\
\hline & & & $2 a$ & 2b \\
\hline \multirow{4}{*}{$\begin{array}{l}\text { Treatment } \\
\text { Success vs. } \\
\quad \text { Fail }\end{array}$} & \multirow{2}{*}{$\begin{array}{c}\text { SVR } \\
\text { Achieved }\end{array}$} & Count & 221 & 51 \\
\hline & & $\begin{array}{c}\% \text { within Interferon } \\
\text { Product }\end{array}$ & $68.4 \%$ & $61.4 \%$ \\
\hline & \multirow{2}{*}{$\begin{array}{l}\text { Failed } \\
\text { Therapy }\end{array}$} & Count & 102 & 32 \\
\hline & & $\begin{array}{c}\% \text { within Interferon } \\
\text { Product }\end{array}$ & $31.6 \%$ & $38.6 \%$ \\
\hline \multirow[t]{2}{*}{ Total } & & Count & 323 & 83 \\
\hline & & $\begin{array}{c}\% \text { within Interferon } \\
\text { Product }\end{array}$ & $100.0 \%$ & $100.0 \%$ \\
\hline
\end{tabular}

Table 5: Binomial test comparing observed SVR rate to standard probability.

\begin{tabular}{|c|c|c|c|c|c|}
\hline & Category & $\mathrm{N}$ & $\begin{array}{c}\text { Observed } \\
\text { Prop. }\end{array}$ & $\begin{array}{c}\text { Test } \\
\text { Prop. }\end{array}$ & $\begin{array}{c}\text { Exact } \\
\text { Sig. }\end{array}$ \\
\hline $\begin{array}{c}\text { Treatment Success } \\
\text { vs. Fail }\end{array}$ & $\begin{array}{c}\text { SVR } \\
\text { Achieved }\end{array}$ & 272 & 0.67 & 0.50 & $0.000^{*}$ \\
\hline & $\begin{array}{c}\text { Failed } \\
\text { Therapy }\end{array}$ & 134 & 0.33 & 0.62 & $0.021^{* *}$ \\
\hline & Total & 406 & 1.00 & 0.55 & $0.000^{* *}$ \\
\hline \multicolumn{7}{|c}{ "two-tailed p value:**one-tailed p value } \\
\hline \multicolumn{5}{|c|}{} \\
\hline
\end{tabular}

\begin{tabular}{|c|c|c|}
\hline \multicolumn{3}{|c|}{ Table 6: Adverse effect frequency table. } \\
\hline & $\begin{array}{c}\text { Telaprevir } \\
\text { n }\end{array}$ & $\begin{array}{c}\text { Boceprevir } \\
\text { n }\end{array}$ \\
\hline Total & $\mathbf{1 1 4}^{*}$ & $\mathbf{2 4}^{*}$ \\
\hline Hematologic & 32 & 10 \\
\hline Rash & 23 & 2 \\
\hline Mental Health & 8 & 3 \\
\hline Flu-Like Symptoms & 5 & 3 \\
\hline Gastrointestinal Symptoms & 7 & 3 \\
\hline Allergic Reaction & 6 & 3 \\
\hline Other/Not Defined & 42 & 4 \\
\hline *Patients may have reported more than one side effect \\
\hline
\end{tabular}

\begin{tabular}{|c|c|c|c|}
\hline \multicolumn{4}{|c|}{ Table 7: Medication Possession Ratio (MPR). } \\
\hline Medication & N & Mean & $\begin{array}{c}\text { Standard } \\
\text { Deviation }\end{array}$ \\
\hline Telaprevir & 239 & $95 \%$ & $9 \%$ \\
\hline Boceprevir & 89 & $91 \%$ & $15 \%$ \\
\hline Peginterferon alfa 2a & 307 & $95 \%$ & $9 \%$ \\
\hline Peginterferon alfa 2b & 79 & $96 \%$ & $9 \%$ \\
\hline Ribavirin & $442 *$ & $95 \%$ & $10 \%$ \\
\hline
\end{tabular}

*Some patients switched between ribavirin products which accounted for multiple MPR calculations

with protease inhibitor based regimens over dual therapy alone in genotype $1 \mathrm{HCV}$ treatment. In this study the observed total SVR rate of patients on triple therapy receiving either telaprevir or boceprevir was $67 \%$ for the total 406 SVR eligible patients. Previous studies of treatment naïve patients resulted in overall SVR rates of $79 \%$ for telaprevir and $63 \%$ and $66 \%$ for boceprevir $[13,15,16]$. In this study, information regarding trial of previous therapy was not collected. Clinical trials have shown that success rates are lower in patients that have previously failed therapy. SVR rates of patients that previously failed dual therapy varied depending on reason for therapy failure and were between 59$86 \%$ for telaprevir and $59-66 \%$ for boceprevir $[14,17]$.

Out of the overall patients initially identified for inclusion in this study, $7.3 \%$ of telaprevir patients and $5.4 \%$ of boceprevir patients discontinued therapy due to adverse events. In the pooled clinical trial results of telaprevir, $14 \%$ of patients receiving telaprevir discontinued due to adverse events [21]. Of those that discontinued the most common adverse events that resulted in therapy discontinuation were rash, anemia, fatigue, pruritus, nausea, and vomiting. However in this study the most frequently reported reason for therapy discontinuation in telaprevir patients was hematologic, which included events such as anemia, neutropenia and thrombocytopenia. For boceprevir, during the entire course of treatment in clinical trials, the proportion of subjects who discontinued treatment due to adverse events was $13 \%$ [22]. Anemia was the only adverse event reported in more than $1 \%$ of those patients that discontinued therapy. This finding is similar to the results reported in this study with the most frequently reported reason being hematologic for boceprevir patients that discontinued therapy. These results may indicate the benefit of clinical counseling on the management of side effects since only a small portion of the patients initially identified discontinued therapy due to adverse effects.

The results also show that adherence rates are similar for both of the protease inhibitor based therapies. The combined average MPR in patients that achieved SVR and those that did not was over $90 \%$ for all medications in the regimen. This result indicates that patients were adherent while on therapy which is especially critical to therapy success.

\section{Limitations}

There are a few limitations of this study that can be identified. The results observed in this study are specific to one specialty 
pharmacy's patient population. However, the patients were distributed nationally. Race and information on previous therapies tried were not obtained in this study although both can indicate potential for therapy success. While data was presented for boceprevir and telaprevir individually, the study was not powered to compare telaprevir based therapy to boceprevir based therapy. Data was obtained solely through utilization data and/or direct outreach to the prescriber, no medical claims were analyzed. Faxed based outreach to the prescriber resulted in limited responses returned which further limited the SVR eligible study population. Finally, a significant number of patients who were on therapy in the study date range were still on therapy at the time of analysis and were thus not eligible for SVR at the time of data collection.

\section{Conclusions}

In conclusion, patients on protease inhibitor-based triple therapy for the treatment of genotype 1 hepatitis $\mathrm{C}$ infection had significantly improved SVR rates compared to previous published dual therapy rates. These findings support the AASLD guideline recommendation of adding a protease inhibitor to ribavirin and pegylated interferon as the standard of care in the treatment of genotype $1 \mathrm{HCV}$ infection [23]. Additional studies that account for the effect of patient ethnicity or previous HCV treatment on SVR rates are warranted to further understand the impact of protease inhibitor treatment on these patient populations.

\section{References}

1. Centers for Disease Control and Prevention (2012) Hepatitis C Information for the Health Professional.

2. McHutchison JG, Everson GT, Gordon SC, Jacobson IM, Sulkowski M,et al.(2009) Telaprevir with peginterferon and ribavirin for chronic HCV genotype 1 infection. N Engl J Med 360(18):1827-1838.

3. Food and Drugs Administration (FDA) 2013. Antiviral Drugs Advisory Committee Meeting Briefing Document. Simeprevir (TMC435): Treatment of Patients with Chronic Hepatitis C.

4. Bialek SR, Terrault NA (2006) The changing epidemiology and natural history of hepatitis C virus infection. Clin Liver Dis 10(4): 697-715.

5. Daniels D, Grytdal S, Wasley A (2009) Surveillance for acute viral hepatitis - United States, 2007. Morbidity and mortality weekly report. Surveillance summaries 58(3): 1-27.

6. Smith BD, Morgan RL, Beckett, GA, Falck-Ytter Y, Holtzman D, et al. (2012) Recommendations for the Identification of Chronic Hepatitis C Virus Infection Among Persons Born During 1945-1965. CDC Morbidity and Mortality Weekly Report (MMWR) 61(RR04): 1-18.

7. Chou R, Cottrell EB, Wasson N, Rahman B, Guise JM (2013) Screening for hepatitis $C$ virus infection in adults: a systematic review for the U.S. Preventive Services Task Force. Ann Intern Med 158(2): 101-108.

8. Backus LI, Boothroyd DB, Phillips BR, Mole LA (2007) Predictors of response of US veterans to treatment for the hepatitis $C$ virus.
Hepatology 46(1): 37-47.

9. Backus LI, Boothroyd DB, Phillips BR, Belperio P, Halloran J, et al. (2011) A sustained virologic response reduces risk of all-cause mortality in patients with hepatitis C. Clin Gastroenterol Hepatol 9(6): 509-516.

10. Veldt BJ, Heathcote EJ, Wedemeyer H, Reichen J, Hofmann WP, et al.(2007) Sustained virologic response and clinical outcomes in patients with chronic hepatitis $C$ and advanced fibrosis. Ann Intern Med 147(10): 677-684.

11. Yee HS, Currie SL, Darling JM, Wright TL (2006) Management and treatment of hepatitis $\mathrm{C}$ viral infection: recommendations from the Department of Veterans Affairs Hepatitis C Resource Center program and the National Hepatitis C Program office. Am J Gastroenterol 101(10):2360-78.

12. Dienstag JL, McHutchison JG (2006) American Gastroenterological Association technical review on the management of hepatitis C. Gastroenterology 130(1):231-64

13. McHutchinson J, Everson G, Gordon E, Jacobson IM, Sulkowski M, et al. (2009) Telaprevir with peginterferon and ribavirin for chronic HCV genotype 1 infection. N Engl J Med 360:1827-1838.

14. Zeuzem S, Andreone P, Pol S, Lawitz E, Diago M, et al.( 2011) Telaprevir for retreatment of HCV infection. N Engl J Med 364(25):2417-2428.

15. Jacobson IM, McHutchison JG, Dusheiko G, et al. (2011) Telaprevir for previously untreated chronic hepatitis $C$ virus infection. N Engl J Med 364(25):2405-2416.

16. Poordad F, Mc Cone J, Bacon BR, Bruno S, Manns M P, et al. (2011) Boceprevir for untreated chronic HCV genotype 1 infection. N Engl J Med 364(13): 1195-1206.

17. Bacon BR, Gordon SC, Lawitz E, Marcellin P, Vierling JM, et al. (2011). Boceprevir for previously treated chronic HCV genotype 1 infection. N Engl J Med. 364(13):1207-1217.

18. Visaria J, Frazee SG (2013) Role of Pharmacy Channel in Adherence to Hepatitis C Regimens. Am J Pharm Benefits 5(1):17-24.

19. McHutchison JG, Manns M, Patel K, et al. (2002) Adherence to combination therapy enhances sustained response in genotype-1infected patients with chronic hepatitis C. Gastroenterology 123(4): 1061-1069.

20. Gordon SC, Yoshida EM, Lawitz EJ, Bacon BR, Sulkowski MS, et al. (2013) Adherence to assigned dosing regimen and sustained virological response among chronic hepatitis $C$ genotype 1 patients treated with boceprevir plus peginterferon alfa-2b/ribavirin. Aliment Pharmacol Ther 38(1):16-27.

21. Telaprevir [package insert]. Cambridge, MA: Vertex; 2012.

22. Victrelis [package insert]. Whitehouse Station, NJ: Schering; 2012.

23. Ghany M, Nelson D, Strader D, et al. (2011) An update on Treatment of Genotype 1 chronic hepatitis C virus infection: 2011 practice guideline by the American association for the study of liver disease. Hepatology 54(4):1433-44. 